\title{
A practical anti-bubble prescription
}

Sandro C. Andrade ${ }^{1}$, Jiangze Bian², Timothy R. Burch ${ }^{1}, 27$ July 2012

Based on "greater fool" theories of bubbles and on data from China's 2007 stock market bubble, we argue that coordinated mass dissemination of information about asset fundamentals should make asset markets less prone to bubbles. This realistic, microlevel anti-bubble policy prescription faces fewer challenges than monetary policy and macro-prudential tools.

A real estate bubble lies at the heart of the current economic slump in the United States (Mian and Sufi, 2011; Mian, Rao, and Sufi, 2011). More generally, Reinhart and Rogoff (2009) find it is common for asset bubbles to precede financial crises and depressions. Typical anti-bubble policy responses include both tightening monetary policy and deploying macro-prudential tools, such as raising capital requirements, imposing transaction costs, and applying direct lending constraints. However, effective application of such policy responses faces two difficulties.

First, timely deployment of monetary policy and macro-prudential tools poses the significant difficulty of regulators recognizing an inflating bubble in real time. Most bubbles are only recognized (with sufficient degree of certainty to justify policy action) in hindsight or when it is too late to prevent damage.

Second, commonly-proposed monetary and macro-prudential anti-bubble measures can create negative effects on regions or markets without bubbles. For example, the very policies that help to fend off a real-estate bubble in overheating regions may retard needed investment and growth in others. In light of this drawback of a one-size-fits-all approach, it is also important to note that calibrating anti-bubble policies on a regionalor industry-basis is likely difficult at best, and politically impossible at worst.

\section{Our proposal and the theory behind it}

We argue that coordinated, mass dissemination of information about asset fundamentals can mitigate bubbles without serious downsides. In real estate markets, for example, this dissemination may be achieved by establishing and promoting a government-sponsored website containing metropolitan-area level real estate statistics and analyses. Such website should aim to be the first stop for the retail investors that populate residential real estate markets.

\footnotetext{
${ }^{1}$ School of Business Administration, University of Miami. E-mails: sca@miami.edu and tburch@miami.edu

${ }^{2}$ School of Banking and Finance, University of International Business and Economics. E-mail: jiangzebian@uibe.edu.cn
} 
Our policy prescription is based on the "greater fool" theory of bubbles. The theory holds that investors knowingly overpay for an asset relative to fundamental value because they believe a yet "greater fool" may arrive in the future to pay even more.

In formalizing the greater fool theory, the "resale option" models of Harrison and Kreps (1978) and Scheinkman and Xiong (2003) separate an asset's equilibrium price into two components: a fundamental value and a resale option value. ${ }^{1}$ The fundamental value is the present value of future asset cash flows and represents the benefit from buying the asset and holding it forever. The resale option value is the "bubble component" of asset prices, and relates to the possibility of reselling the asset later at a higher price. It is positive when there are short-selling constraints and (current or prospective) disagreement across investors about fundamental values.

A key insight in these models is that when such investor disagreement is greater, so too is an asset's resale option value and hence its bubble component. Thus, to the extent that it reduces investor disagreement, greater public dissemination of information about fundamentals can mitigate bubbles. Greater dissemination of information will reduce disagreement as long as it coordinates investors' beliefs, i.e., as long as investors update their priors towards the information being disseminated. Note that, perhaps surprisingly, it isn't required the information necessarily has to be $100 \%$ accurate with respect to what the true fundamental value is. The key is simply that the information disseminated is helpful in coordinating beliefs.

\section{Empirical support}

In Andrade, Bian, and Burch (2012) we test the notion that greater information of dissemination of information can mitigate bubbles by reducing investor disagreement. We undertake a cross-sectional study of the China's 2007 stock market, which displayed several classic features of a pronounced bubble. Over a six-month period, stock prices nearly tripled and trading activity nearly quadrupled, only to return to "normal" levels after the bubble deflated. Over the same six-month period, there was a large influx of novice investors venturing into the stock market, as evidenced by the opening of new trading accounts and the surge of web searches for the terms "stock" and "stock market".

Our primary analysis investigates whether Chinese stocks with greater degree of information dissemination about asset fundamentals experienced smaller bubbles. The 2007 Chinese setting is particularly attractive because it allows us to measure stocklevel bubble intensity in several different ways, some of them unavailable in other 
settings such as the U.S. tech stock bubble. The fact that we find consistent results using all of these bubble intensity metrics strengthens our conclusions.

\section{Main finding}

Figure 1 illustrates our main finding. It shows how bubble intensity is cross-sectionally related to information dissemination. Here, bubble intensity is measured by Composite bubble measure, our main stock-level bubble intensity metric. Analyst coverage, the number of brokerage analysts following the stock, is the literature's most popular crosssectional measure of dissemination of information about stock fundamentals. Stock analysts are specialized professionals who collect information about stocks and disseminate it to market participants in the form of periodic reports, earnings forecasts, and buy/sell/hold recommendations. ${ }^{2}$
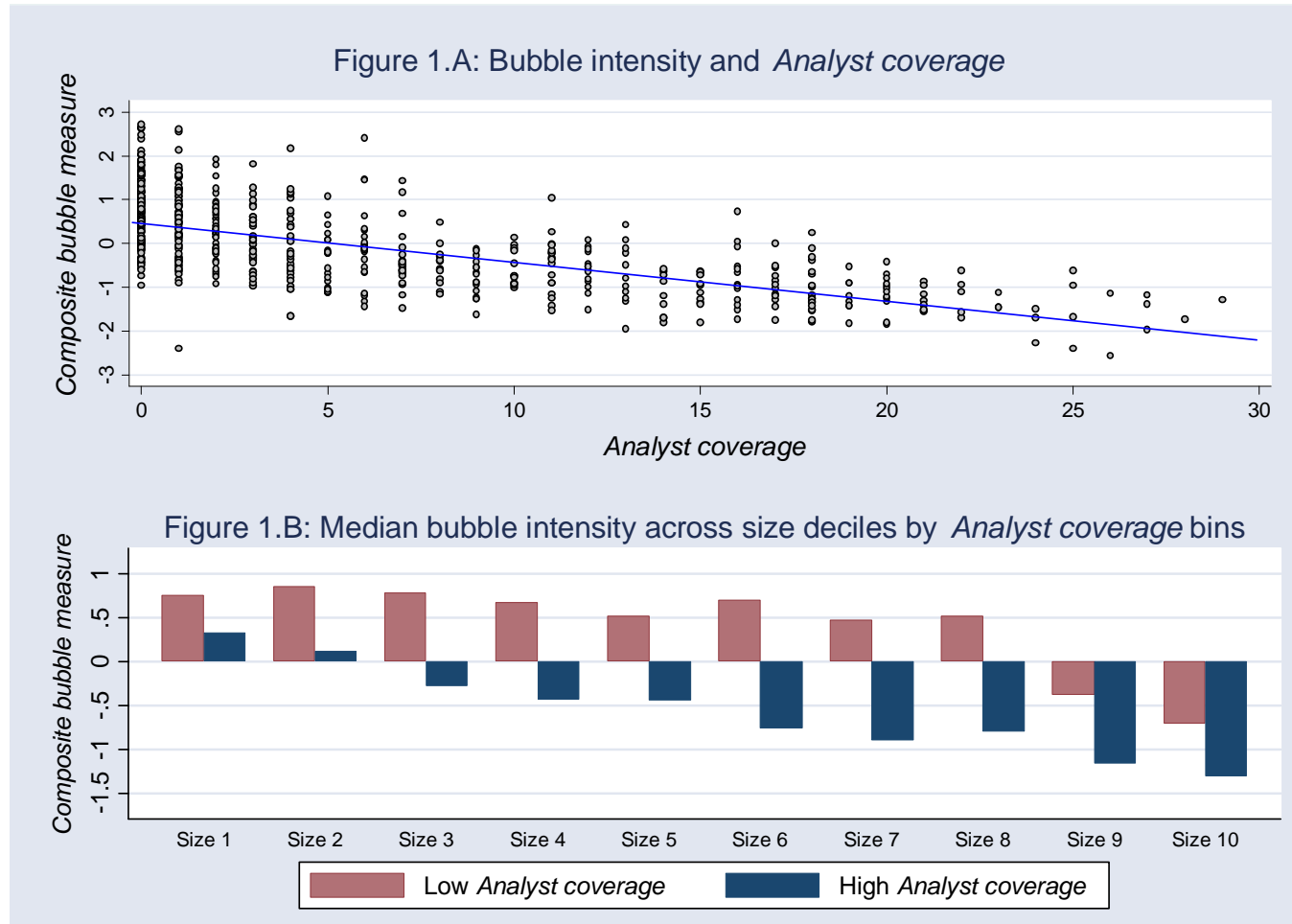

Figure1.A shows that stocks with greater Analyst coverage developed smaller bubbles. Note that Composite bubble measure has been normalized to have zero mean and unity variance, so that negative values simply imply bubble intensities below the crosssectional mean.

Figure 1.B shows that the positive correlation between Composite bubble measure and Analyst coverage does not obtain merely because larger stocks developed smaller bubbles and have greater analyst following. To produce this figure, we sort stocks into 
10 size bins, and within each size bin we further sub-divide stocks into High and Low analyst coverage bins depending on whether Analyst coverage is below or above the bin's median. The figure shows that, across all 10 size bins, stocks with High Analyst coverage experience smaller bubbles than stocks with Low Analyst coverage. ${ }^{3}$

\section{The mechanism}

Additional findings in the paper support the notion that information disseminated by analysts mitigates bubbles because it reduces investor disagreement, as the "greater fool" theory predicts. For example, greater disagreement among stock analysts about the firm's future stock returns or earnings should adversely affect the degree to which a given amount of analyst coverage coordinates investors' beliefs. I.e., for a given number of analysts, the information that they disseminate should be less effective in reducing investor disagreement (and hence mitigating bubbles) when analysts themselves disagree more. Indeed, the data show that analyst coverage was less effective in mitigating bubbles when there was more disagreement among analysts. We also find that, all else equal, stocks with greater analyst coverage experienced lower turnover, a good proxy for current (but not prospective) disagreement about fundamentals.

\section{What about identification?}

Of course, analyst following is not randomly assigned across stocks. In the paper we provide a battery of additional tests that address the possibility that our results obtain merely because Analyst coverage is endogenously correlated with bubble intensity. For example, we confirm our results using two different instruments for Analyst coverage and 2SLS regressions. Moreover, we investigate three specific alternative stories based on non-causal relationships between Analyst coverage and bubble intensity. None of these stories withstand further scrutiny.

\section{Conclusion}

We argue that to make asset markets less prone to bubbles, governments and regulatory bodies should actively sponsor the dissemination of information about asset fundamentals. In stock markets, governments and exchanges should actively subsidize and disseminate professional analyst research when brokerage firms do not themselves

find it profitable to disseminate such research. ${ }^{4}$ In real estate markets, governments and regulatory bodies should take measures to level the playing field for all participants in these markets. This could be achieved by establishing and promoting a website containing information about transactions, appraisals, rental yields, vacancies, demographic/migration trends, prospective changes in zoning laws, and real-property 
borrowing statistics; as well as simple analyses. To the extent that such website becomes the first stop for investors participating in real estate markets, our policy prescription may go a long way in reducing the odds and severity of future real estate bubbles.

\section{References}

Sandro C. Andrade, Jiangze Bian, and Timothy R. Burch, 2012, "Analyst Coverage, Information, and Bubbles," Journal of Financial and Quantitative Analysis, forthcoming.

J. Michael Harrison and David Kreps, 1978, "Speculative Investor Behavior in a Stock Market with Heterogeneous Expectations," Quarterly Journal of Economics 92, 323-339.

Atif Mian and Amir Sufi, 2011, "What Explains High Unemployment? The Aggregate Demand Channel," Working paper, University of Chicago.

Atif Mian, Kamalesh Rao, and Amir Sufi, 2011, "Household Balance Sheets, Consumption, and the Economic Slump", Working paper, University of Chicago.

Jose A. Scheinkman and Wei Xiong, 2003, "Overconfidence and Speculative Bubbles," Journal of Political Economy 111, 1183-1219.

Carmen Reinhart and Kenneth Rogoff, 2009, This Time Is Different: Eight Centuries of Financial Folly, Princeton University Press.

\footnotetext{
${ }^{1}$ In the paper we provide a simplified two-state, two-period version of Scheinkman and Xiong's (2003) model. In that model the decomposition of price into fundamental value and the resale option value is straightforward.

${ }^{2}$ During the period we study, such analyst research was not only available to investors through their brokerage firms, but also through freely-accessible, web sites.

${ }^{3}$ Please see the paper for regressions in which we include several other control variables in addition to size.

${ }^{4}$ Some exchanges, namely London Stock Exchange's AIM and the major exchanges in Singapore and Malaysia, directly or indirectly sponsor, subsidize, or help organize the provision of analyst coverage.
} 